\title{
An Investigation of the Effect of Transcribing Listening on Iranian EFL Learners' Listening Skill
}

\author{
Davoud Shafiee \\ University of Kashan, Kashan, Iran \\ E-mail: davoud_shafiee@yahoo.com
}

Ali Rahimi $(\mathrm{PhD})$

University of Kashan, Kashan, Iran

Received: 17-07- 2012

Accepted: 04-08- 2012

Published: 01-11- 2012

doi:10.7575/ijalel.v.1n.6p.99

URL: http://dx.doi.org/10.7575/ijalel.v.1n.6p.99

\begin{abstract}
Some studies have shown that transcription of listening sections in EFL situations improves the listening skill dramatically. Some teachers at language institutes have examined this method of listening improvement and at the end of the term discerned the outstanding progress in learners' listening skill. This paper takes two fifteen-learner advanced EFL classes into consideration to find out the extent to which learners' listening skill can be affected by listening parts they transcribed during the term. In one the classrooms, before listening to the listening sections, learners transcribed them at home beforehand and left a blank for words they couldn't understand. Then they took those transcriptions to the classroom for revision and filling the blanks. Findings of this study exhibited that those learners who did the job of transcribing during the term could improve their listening skill much more than those who didn't. This method also helps learners improve their concentration during the listening, their speed of writing, and finally their spelling.
\end{abstract}

Keywords: Listening, Deep listening, Language proficiency, EFL, Transcription.

\section{Introduction}

Since some EFL learners have troubles with listening comprehension and are not able to determine what listening strategies fulfill their need for ever, this paper aims to put forward an efficient method which can improve learners' listening deeply and radically, and whose effects could be observed in other language areas, too. In other words, one can benefit in several ways applying this method.

According to Temple \& Gillet (1989) transcribing "is an excellent activity that helps learners sharpen their listening, handwriting, spelling, and punctuation all at once. When transcribing, or taking dictation, is used primarily as a listening activity, teachers should put emphasis on the accuracy of their listening and de-emphasize the encoding aspects of handwriting, spelling, and punctuation. If we demand a high degree of accuracy in all these aspects, we can make transcribing a very difficult and frustrating task. Focus on the main point, good listening and work on neatness and accurate spelling at another time" (p. 103-104).

For our purposes, a working definition of bottom-up processing is the word-level linear processing of a piece of spoken language through transcription with the goal of accurately recording and comprehending the whole (Mendelsohn, 1994). Andersen \& Lynch (1988) provide a useful summary of bottom-up processing by describing it as "listener as tape recorder." Bottom-up processing (transcription) is exercised through Deep Listening, inspired by the "Ango Kaidoku system" as conceived by Gregory Clark $(1993,1996)$, and further developed by some authors (Hoskins, Maeda, \& Johnson, 2006). Aside from being an intriguing name, the term Deep Listening is intended to convey to learners the idea that they need to concentrate deeply while working through the exercises, especially the lecture-dictation section of each unit. Reliance on transcription for listening training in foreign language acquisition and second language acquisition has a long history. Rost (2002) refers to it as the "prototypical intensive listening activity." Other researchers (e.g., Cohen, 1994; Buck, 1992) have pointed out the superiority of dictation (transcription) as an integrative exercise of listening due to its inclusion of listening along

\footnotetext{
Page $\mid 99$

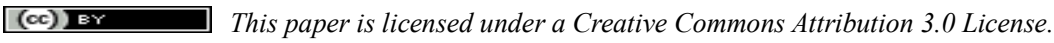


with the processing of grammar, vocabulary, and making inferences from context. After completing the DL (Deep Listening) dictation, listen again while reading through their self-corrected dictations, highlighting or otherwise noting those words and phrases that were previously incomprehensible, and experiencing them again, thus providing aural as well as visual and kinesthetic confirmation. Kelly (1991) asked advanced French speakers of English to transcribe and/or translate BBC radio news recordings and other listening comprehension texts and counted the number of errors they made concerning perceptual, lexical and syntactical accounts respectively. Allowing the participants to listen at their own pace and to relisten when necessary, Kelly could control the general knowledge variable and successfully isolate lexical ability as the major factor influencing the participants' listening comprehension.

\section{Method}

This part elaborates on how the study was conducted. The first part of method takes participants into consideration and describes them completely. Next section of method clarifies what instruments were used to conduct the study. Finally, it considers the procedures and steps employed to carry out the study.

\subsection{Participants}

As mentioned before, in this study two advanced EFL classes (ESL 10) from Sadr English institute, Esfahan, Iran were examined. In this institute, classes range from ESL 1 (Elementary) to ESL 12 (Advanced). ESL here stands for English as a second language. Although they are studying English as a Foreign Language, this is the term of which this institute has made use.

In each classroom, there were fifteen male Persian-speaking learners ranging from the age of 19 to 29 . Therefore, totally in both classes there were 30 learners. These learners had passed the placement test given to them to make sure they were all at the same level of proficiency in both classes. In this institute, before going to the next term, learners are given an oral Placement test to make sure they are at the same level of proficiency.

\subsection{Instrumentation}

Two listening sections based on ESL 11 book which were somehow at the same level of difficulty were selected. One of them was played to learners before the term (ESL 10) started, and the other after the term finished. The books studied by learners from ESL 9 to 12 were Passages (Second Edition) by Richards and Sandy (2005). In addition, at the end of the term, learners were interviewed to find out their impressions concerning this task, and the effects it had on their English.

\subsection{Procedure}

Before the term started, these learners listened to a listening section which was one level higher than the listening parts to which they were going to listen. These learners were going to attend ESL 10 classes, but for this study the listening sections were extracted from ESL 11. The listening extracts were one level higher than the listening sections they were going to listen to in ESL 10 to make sure that they hadn't listened to it before. As a result, there appeared some words in the listening that were unknown to learners. After listening to the extract, each of the learners were asked six same questions to find out how many they could answer correctly. The listening extract the learners listened to could only be covered by six questions; for example, if five questions had been asked, some parts would have been missed. After a term of transcribing listening sections in ESL 10, they listened to a listening extract taken from ESL 11 with the same level of difficulty as what they listened to before the term. Again, they were asked six questions associated with the second extract. The length of these two listening extracts was the same (about five minutes) and they both referred to the same topic i.e. two different speakers had voiced their ideas about that same topic. Moreover, the teacher didn't tell learners where he took the listening extracts from, and they were not told that they were going to listen to another extract after the term.

The first extract was played to learners in both classes before the first session of the term (ESL 10) began. All learners listened to it and could take notes while listening. After the listening, one of the learners stayed in the class and all the others went out. The teacher asked the learner those six questions and based on correct answers, he gave him a score. Every correct answer had one point, so the maximum score one could earn was 6 . After answering the questions, the first learner didn't go out, but took a seat at the back the classroom. In this way, no one could reveal the questions to other learners. Then, the second learner entered the classroom and after answering the questions, he, too, sat at the back of the class next to the first learner, and it continued until all learners did that. 
During the term, class A transcribed all listening sections. They transcribed the listening of the following sessions in advance by playing the listening backward and forward. They left a blank for those words they didn't understand. Later in the class, they again listened to the listening twice. First, the teacher played it all to the learners without any pauses and asked them "what happened in the listening? "Nearly all learners retold some parts of the story in the listening section. Next, the teacher played the listening again; however, this time with frequent pauses. In this way, the teacher could help learners fill in the blanks with the unknown words and he also had the opportunity to tell them what the new words meant. This method of filling in the blanks is very similar to "Partial Dictation" in which learners are given a passage with some deletion. Then, someone reads the whole passage to test-takers and they are expected to complete the blanks with missing words.

However, in class B, learners didn't transcribe listening sections and attended the class even without listening to the listening sections beforehand. They listened to listening sections twice in the class, once to retell the story and the other time to learn the new words found in the listening. During the first listening they could take notes if they wished.

After the term, both class A and B listened to the second extract and answered another set of six questions related to the extract. And again, the teacher specified some scores to the learners based on their right answers. The teacher didn't tell learners that this entire task was a research until he examined all learners' listening comprehension after the term.

\section{Results}

As mentioned before, learners' listening comprehension was tested before and after the term by asking them 6 questions related to those listening extracts. As illustrated in table 1, each learner in each class received two scores; one of them before and the other after the term. In class A, thirteen learners got higher scores (learners A, B, C, D, $\mathrm{G}, \mathrm{H}, \mathrm{I}, \mathrm{J}, \mathrm{K}, \mathrm{L}, \mathrm{M}, \mathrm{N}$, and $\mathrm{O}$ ), one learner (F) received the same score, and one learner (E) got a lower score. In this class four learners $(26.66 \%$ of learners in class A. Learner B, G, H, and O) received scores that were three points higher than the scores they got before the term. Eight Learners $(53.36 \%, \mathrm{~A}, \mathrm{C}, \mathrm{D}, \mathrm{I}, \mathrm{J}, \mathrm{K}, \mathrm{L}, \mathrm{M})$ got scores that were two points higher; and one learner $(6.66 \%, \mathrm{~N})$ got a score that was one point higher. Thus, totally, $86.66 \%$ of learners in class A got higher scores, $6.66 \%$ got same scores, and $6.66 \%$ got lower scores. The average in class $\mathrm{A}$ was 2.6 before the term and 4.46 after that with the standard deviation of 0.98 before and 1.45 after the term. In class B, on the other hand; only eight learners (Learner A, D, E, G, H, J, K, and O) got higher scores than the ones they earned before the term, four learners $(\mathrm{B}, \mathrm{F}, \mathrm{I}$, and $\mathrm{M})$ received the same scores, and three learners $(\mathrm{C}, \mathrm{L}$, and $\mathrm{N})$ got lower scores. Very interestingly, in this class no one $(0 \%)$ got a score that was three points higher than the score he received before the term. Two learners $(13.3 \%, \mathrm{E}, \mathrm{K})$ earned scores that were two points higher, and six learners ( $40 \%, \mathrm{~A}, \mathrm{D}, \mathrm{G}, \mathrm{H}, \mathrm{J}$, and O) obtained scores that were only one mark higher. Therefore, $53.3 \%$ of learners in class B ended up with higher scores, which is very lower than what we observed in class A. Also, in class B, $26.6 \%$ of learners gained same scores, and $20 \%$ received lower scores, which is a greater percentage in comparison with class A. The average in class B was 3.13 before and 3.6 after the term with standard deviation of 1.29 before and 1.63 after that.

Table 1: Learners' scores before and after the term.

\begin{tabular}{|c|c|c|c|c|c|c|c|c|c|c|c|c|c|c|c|c|}
\hline Learners & & A & B & $\mathrm{C}$ & $\mathrm{D}$ & $E$ & $\mathrm{~F}$ & $\mathrm{G}$ & $\mathrm{H}$ & $\mathrm{I}$ & $\mathrm{J}$ & $\mathrm{K}$ & $\mathrm{L}$ & $\mathrm{M}$ & $\mathrm{N}$ & $\mathrm{O}$ \\
\hline \multirow{3}{*}{ Class A } & Before & 2 & 3 & 4 & 3 & 2 & 4 & 3 & 3 & 2 & 4 & 3 & 2 & 1 & 2 & 1 \\
\hline & & & & & & & & & & & & & & & & \\
\hline & After & 4 & 6 & 6 & 5 & 1 & 4 & 6 & 6 & 4 & 6 & 5 & 4 & 3 & 3 & 4 \\
\hline \multirow{2}{*}{ Class B } & Before & 3 & 4 & 3 & 5 & 4 & 3 & 4 & 2 & 4 & 1 & 3 & 2 & 1 & 6 & 2 \\
\hline & After & 4 & 4 & 2 & 6 & 6 & 3 & 5 & 3 & 4 & 2 & 5 & 1 & 1 & 5 & 3 \\
\hline
\end{tabular}


International Journal of Applied Linguistics \& English Literature

ISSN 2200-3592 (Print), ISSN 2200-3452 (Online)

Vol. 1 No. 6; November 2012

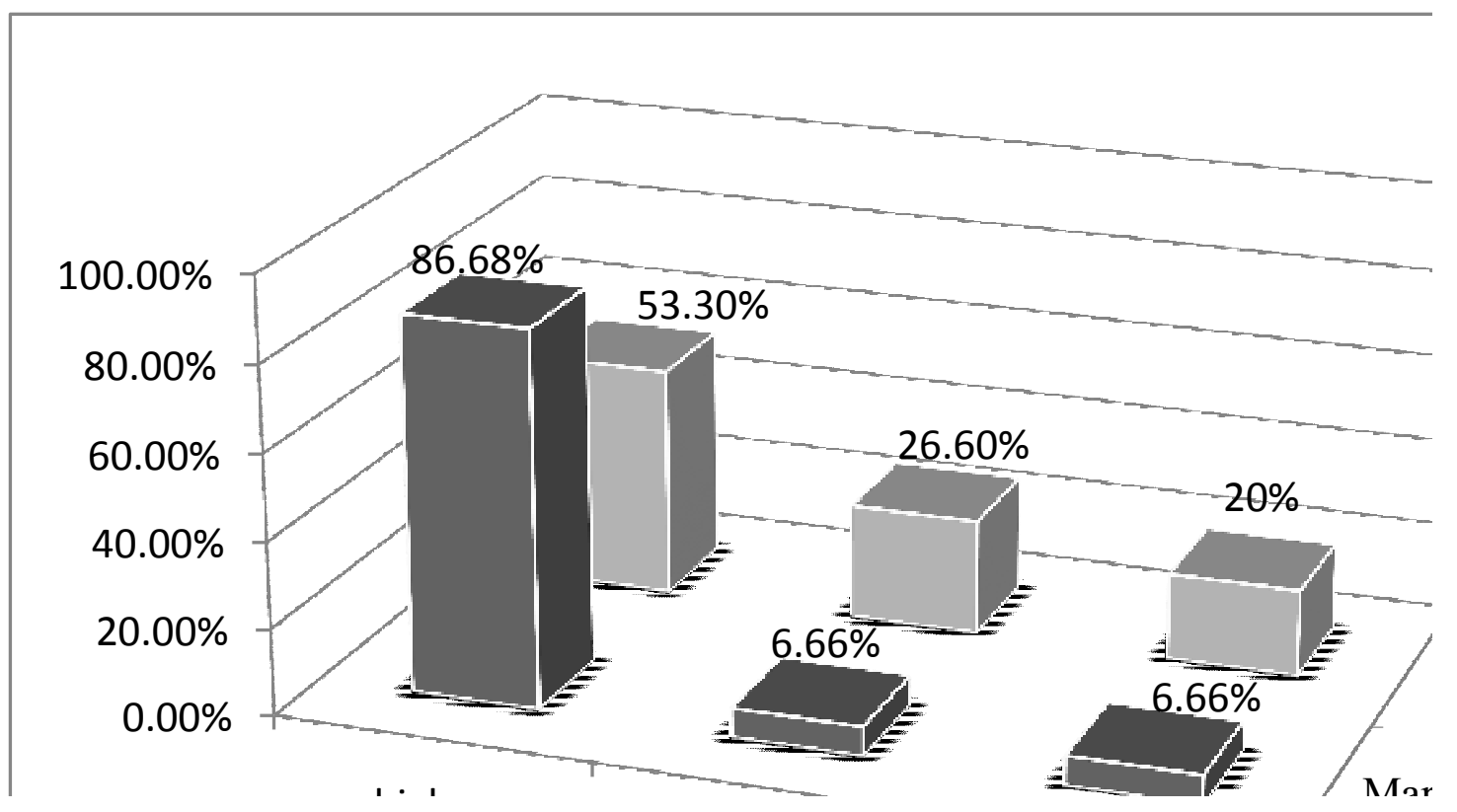

Chart 1 . Both classes' percentages more clearly

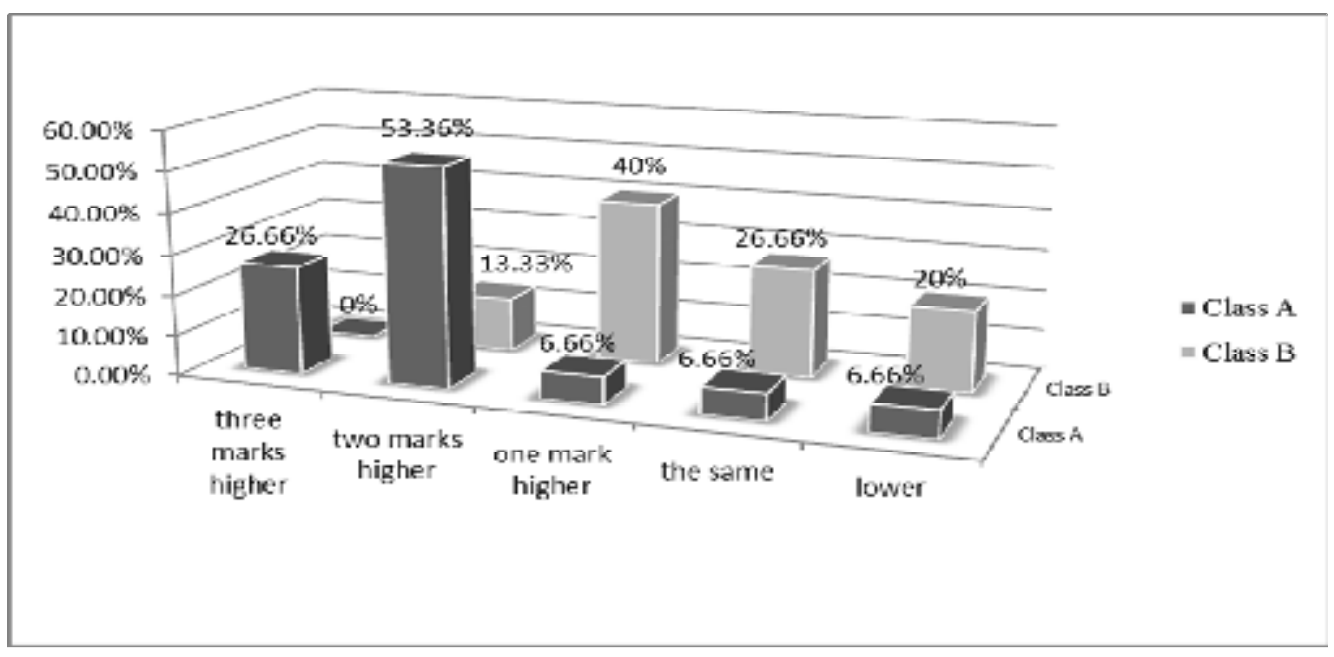

Chart 2. Learners' mark differences before and after the term.

The results of two paired samples tests demonstrate a significant difference for class A but not for class B as follows:

Table 2. Paired samples t-test for class A

\section{Paired Differences}

$95 \%$ Confidence Interval of the

Difference

\begin{tabular}{ccccccc} 
& & Lower & Upper & t & df & Sig. (2-tailed) \\
\hline Pair 1 & After A - before A & 1.243 & 2.490 & 6.424 & 14 & $<0.001 * *$ \\
\hline
\end{tabular}


International Journal of Applied Linguistics \& English Literature

ISSN 2200-3592 (Print), ISSN 2200-3452 (Online)

Vol. 1 No. 6; November 2012

As you can see, in class $\mathrm{A}$, the P-value equals 0.001 which is way less than 0.05 , which depicts a significant difference between the scores before and after the term. Nevertheless, according to table 3 below, no significant difference was observed in class B regarding scores before and after the term.

Table3. Paired samples t-test for class B

\begin{tabular}{|c|c|c|c|c|c|c|}
\hline & & Pair & nces & & & \\
\hline & & $95 \%$ Conf & arval of & & & \\
\hline & & Lower & Upper & $\mathrm{t}$ & $\mathrm{df}$ & Sig. (2-tailed) \\
\hline Pair 1 & After B - before B & -.082 & 1.015 & 1.825 & 14 & .089 \\
\hline
\end{tabular}

Since the P-value here is 0.089 which is more than 0.05 , there was no significant difference between the scores before and after the term in class B.

An Independent samples t-test was applied to decipher which class had more progress in scores. Table 4 shows the results:

Table 4. Independent Samples t-test

\begin{tabular}{ccccc}
\hline & & \multicolumn{3}{c}{ t-test for Equality of Means } \\
& & & & Std. Error \\
& & Sig. (2-tailed) & Mean Difference & Difference \\
\hline \multirow{2}{*}{ diffA } & Equal variances assumed & $.001^{* *}$ & 1.4 & .387 \\
& Equal variances not assumed & .001 & 1.400 & .387
\end{tabular}

As you can see, the mean difference (progress) in class A is 1.4 scores more than class B. The P-value $(0.001)$ also demonstrates a significant difference between the two classes' scores after the term.

\section{Discussion}

This study investigated whether transcribing listening sections in an EFL situation affects the listening comprehension improvement or not. The results revealed that those learners who did the task of transcription during the term improved their listening skill significantly higher than those learners in class B who even didn't know how to transcribe a listening section. Based on the data demonstrated in charts and tables of the previous section of this paper, one can easily come to a conclusion that class B learners' listening comprehension didn't change to a great extent, on the other hand; class A learners' listening comprehension had an incredible progress in a way that nearly $27 \%$ of the learners got scores that were three points higher than the scores they had received before the term began while nobody in class B could achieve a three-point improvement. Class A had again a striking record among those learners who could progress two points. $53.36 \%$ of learners had a two-point progress in this class while in class B this number was $13.33 \%$. It signifies that the two-point improvement was four times more in class A than the one in class B. This great discrepancy represents the great effect of the listening transcription on learners' listening comprehension. While class A had most of its progress in three and two-point improvement, class B had it in one-point improvement which indicates that the listening development had a very slow pace in this class. Another strong evidence that authenticates the effect of this activity on listening is the percentage of those learners who didn't make any progress in their listening comprehension. In class A these learners constitute $6.66 \%$ of the class while this number was $26.66 \%$ in class $\mathrm{B}$. This strong proof reveals again that listening progression in class A was about five times more than the one in class B. Moreover, another confirmation that adds weight to the legitimacy of this study is the deterioration of listening comprehension in both classes. In class A, only did one of the learners (6.66\% of the learners) suffer from the listening comprehension regression, on the other hand; in class B three learners $(20 \%)$ had to cope with this 
problem. As a result, all the statistical data provided above corroborate the positive and conducive effect of transcription on the listening skill.

When asked about their impression through the interview, nearly all learners in class A had a very great feeling about the task and wanted to continue the task while learning English. When asked about the effect of transcription, they said that in addition to listening improvement, they managed to enhance their concentration during the listening. They said before they started this task, they had had many problems focusing on the topic and what the speaker said in the listening sections. Nevertheless, after this term, they could ignore both the external distracters (e.g. noise) and the internal ones (such as disturbing thoughts) and listened deeply to what they were to transcribe. Another advantage that some learners mentioned was the development in spelling. They said before that term, they had had numerous problems with the spelling of some specific words; however, they could finally learn how to write them down for they had to write those particular words frequently in different listening sections. Another benefit according to learners was their advancement in all the other four skills (listening, speaking, reading, and writing) among which listening improvement was the one which appeared more noticeable.

Although the effect of transcription on listening was impressive, there appeared to be some problems mentioned by learners. Some learners said that this task was a little bit burdensome and time-consuming at the beginning, but after transcribing some listening, they could get accustomed to it. Other learners construed this problem as an advantage; they said since they were exposed to the listening parts frequently, they could improve their language proficiency. Krashen and Terrell (1983) hold in natural approach that frequent exposure to comprehensible input and the input which is one level beyond the learners' present knowledge provide the necessary and sufficient conditions for successful classroom second and foreign language acquisition. And this is exactly what we can obviously notice in this method. Another problem that another group of learners were complaining about was the feeling that they were not making any progress or that they didn't know whether they were making any progress or not. An explanation to this awkward feeling is that the progress made by learners during that term was subtle. Since the term lasted for about two and a half month, they couldn't feel the gradual progress they made during that long time. Usually, learners like to learn native-like English overnight, that is why they sometimes complain about the slow-moving improvement. Surprisingly, among those who complained were learners B and O who achieved a three-mark improvement after the term and they were amazed to see they accomplished that progress.

Although learners in class A improved their listening significantly, we ought not to take class B listening improvement for granted. They took notes during the term while listening to the listening sections or even listened carefully without taking any notes. Despite this, they made a trivial progress in comparison with class A. This comparison can be an alarm for those teachers who don't employ any strategies at all while dealing with the listening sections.

Here are some alternative ways of transcription by English Language Arts (2002):

Teachers can:

- $\quad$ use different types of material for transcription, particularly material they want learners to remember and use when they practice writing

- include material that is fun to listen to and easy to remember, such as short poems, jump-rope rhymes, limericks, tongue twisters, nursery rhymes, riddles, and even recipes

- Let learners dictate stories to each other, and then have them work together to proofread and correct listening errors.

\section{Conclusion}

The present study addressed one of the ways of ameliorating the listening skill by employing transcription as the major task in EFL situations. As seen before, this activity addressed nearly all scopes of language from spelling to speaking, however; its main concern was listening comprehension. As the results showed before, this method can be really effective, but it doesn't mean that other strategies have to be abandoned at all. However, its impacts on listening were worthy of attention in comparison with other strategies such as note-taking or mere listening conducted in class B. Every class in EFL situations ought to pick out the most conducive method in which learners are the most interested. But, interest is not the only criterion for a teacher to select a method. There are other criteria such as practicality, validity, and efficiency that a teacher should take into consideration. This strategy is more fruitful to intermediate and advanced levesl because in elementary levels learners have more 


\section{International Journal of Applied Linguistics \& English Literature \\ ISSN 2200-3592 (Print), ISSN 2200-3452 (Online) \\ Vol. 1 No. 6; November 2012}

basic tasks to spend their time on. This study has certainly paved the way for others to scrutinize the effects of transcription on other areas of language, for all areas and skills in a language are somewhat related; therefore, some findings in one area can lead one to findings in other areas.

\section{References}

Anderson, A. \& T. Lynch. (1988). Listening. Oxford University Press.

Buck, G. (1992). Listening comprehension: Construct validity and trait characteristics. Language Learning, 42(3), 313-57.

Clark, G. (1993). The Ango Kaidoku technique for learning foreign languages. Tokyo: Dobun-Shoin.

Clark, G. (1996). Clark-sensei no eigo benkyo kakumei. Tokyo: Goma-Shobo.

Cohen, A. (1994). Assessing language ability in the classroom. Boston, NJ: Heinle \& Heinle.

Hoskins, C., Maeda, Y., \& Johnson, I. (2006). Deep Listening in Focused Listening Classes at Akita International University. Akita English Studies, 48, 28-35.

Kelly, P. (1991). Lexical ignorance: the main obstacle to listening comprehension with advanced foreign language learners. International Review of Applied Linguistics, 29 (2), 135-49.

Krashen, S. (1982). Principles and practice in second language acquisition. Oxford: Pergamon Press.

Mendelsohn, D. (1994). Learning to listen. Carlsbad, CA: Dominie Press.

Richards, J.C., Sandy, C. (2005). Passages (Second Edition).Cambridge: Cambridge University Press.

Rost, M. (2002). Teaching and researching listening. Harrow, UK: Pearson Education.

Temple \& Gillet. (1989). "English language arts 10: a bibliography for the secondary level. Retrieved November 18, 2010 from http://www.sasked.gov.sk.ca/docs/xla/ela15b.html.

Terrell, T.D. (1982). The natural approach to language teaching: an update. Modern Language Journal, 66 (2), $121-132$. 